\title{
Prospective evaluation of changes in choroidal vascularity index after half-dose photodynamic therapy versus micropulse laser treatment in chronic central serous chorioretinopathy
}

\author{
Thomas J. van Rijssen ${ }^{1}$ • Sumit Randhir Singh ${ }^{2}$ • Elon H. C. van Dijk ${ }^{1} \cdot$ Mohammed A. Rasheed $^{2}$ • \\ Kiran Kumar Vupparaboina ${ }^{2}$. Camiel J. F. Boon ${ }^{1,3} \cdot$ Jay Chhablani $^{4}$
}

Received: 11 October 2019 / Revised: 20 January 2020 / Accepted: 2 February 2020 / Published online: 13 March 2020

(C) The Author(s) 2020

\begin{abstract}
Purpose To assess whether treatment of chronic central serous chorioretinopathy (cCSC) with photodynamic therapy (PDT) and high-density subthreshold micropulse laser (HSML) results in choroidal vascularity index (CVI) changes that may account for the treatment effect.

Methods Patients with cCSC were prospectively included and analyzed. Patients received either half-dose PDT or HSML treatment. CVI of the affected and unaffected eye was obtained before treatment, 6 to 8 weeks after treatment, and 7 to 8 months after treatment. Results At baseline, 29 eyes (29 patients) were included both in the PDT and in the HSML group. The mean ( \pm standard deviation) CVI change in the HSML group between before PDT and 6 to 8 weeks after PDT was $-0.009 \pm 0.032(p=0.127)$, whereas this was $0.0025 \pm 0.037(p=0.723)$ between the visit before PDT and final visit. The patients in the PDT group had a CVI change of $-0.0025 \pm 0.037(p=0.723)$ between the visit before PDT and first visit after PDT, and a mean CVI change of $0.013 \pm 0.038(p=0.080)$ between the visit before PDT and final visit. There was no significant correlation between CVI and BCVA at the measured time points, in both the HSML group $(p=0.885)$, and in the PDT group $(p=0.904)$. Moreover, no significant changes in CVI occurred in the unaffected eye at any time point.

Conclusions PDT and HSML do not significantly affect CVI, and therefore a CVI change may not be primarily responsible for the treatment effect. The positive treatment effect of both interventions may rely on other mechanisms, such as an effect on choriocapillaris and/or retinal pigment epithelium function.
\end{abstract}

Keywords Central serous chorioretinopathy $\cdot$ Choroidal vascularity index $\cdot$ Micropulse laser $\cdot$ Photodynamic therapy

\section{Introduction}

Central serous chorioretinopathy (CSC) is characterized by the presence of subretinal fluid (SRF), presumably caused

Camiel J. F. Boon

c.j.f.boon@lumc.nl

1 Department of Ophthalmology, Leiden University Medical Center, Leiden, the Netherlands

2 Department of Ophthalmology, L.V. Prasad Eye Institute, Hyderabad, India

3 Department of Ophthalmology, Academic Medical Center, University of Amsterdam, Amsterdam, the Netherlands

4 Department of Ophthalmology, University of Pittsburgh, UPMC Eye Center, Pittsburgh, PA, USA by underlying choroidal abnormalities that lead to damage to the retinal pigment epithelium (RPE) [1]. CSC has been associated with multiple risk factors including male gender, type A personality, steroid use, Cushing disease, and genetic predisposition [2-5]. For this chorioretinal disease, variable practice patterns exist among clinicians [6]. Photodynamic therapy (PDT) [7-10], high-density subthreshold micropulse laser (HSML) [11-14], and mineralocorticoid antagonist-like eplerenone have been used to treat chronic CSC [4, 15-17]. However, treatment options are not uniformly successful with variable and suboptimal outcomes, and different thoughts about the desired effect of treatment $[18,19]$. These controversies regarding the first-line treatment modality for chronic CSC exist till date due to lack of level I evidence [19].

The half-dose photodynamic therapy versus high-density subthreshold micropulse laser treatment in patients with chronic central serous chorioretinopathy (PLACE) study was 
a prospective, randomized controlled trial conducted in 5 centers across Europe [20,21]. The superiority study compared half-dose photodynamic therapy with high-density subthreshold micropulse laser treatment. The primary outcome measure being studied was complete resolution of SRF as measured on optical coherence tomography (OCT) at the first evaluation visit at 6 to 8 weeks after first treatment. Moreover, complete resolution of SRF on OCT at final follow-up at 7 to 8 months after first treatment and best-corrected visual acuity (BCVA), retinal sensitivity on microperimetry, and visual functioning through a validated questionnaire at the first evaluation visit were the secondary study outcome parameters [21]. According to the results of the PLACE trial, half-dose PDT is superior to HSML treatment both in terms of anatomical and functional outcome [20]. However, the analysis of choroidal vasculature, including choroidal vascularity index (CVI) was not part of the study.

$\mathrm{CVI}$ and lumen/choroid ratio have been described as ratios to assess the luminal area versus total choroidal area [22-25]. The ratio expressed as a percentage usually varies from 64 to $67 \%$ in normal individuals and is known to alter in various pathologies including CSC [22-24, 26, 27]. It has been proposed earlier that CVI may act as an indicator of disease activity in CSC [26]. This was based on the assumption that choroidal vascular hyperpermeability forms the main pathogenetic conduit for onset of CSC, and thus monitoring the changes in CVI over a period of time may be useful to provide information about the disease.

In the present study, we evaluated the changes in CVI after PDT and HSML and analyzed variables that may have a positive effect on changes in BCVA. The changes in CVI during follow-up may help predicting both the response to several treatments and disease progression.

\section{Methods}

The PLACE trial was a randomized controlled trial comparing half-dose PDT with HSML [21]. The subjects included in this study were recruited from 5 centers across Europe from November 22, 2013 to September 15, 2016 [21]. In the present study, we have analyzed a subset of PLACE trial patients originating from 1 of the participating centers (Leiden University Medical Center, Leiden, Netherlands).

\section{Study design}

The details on the study design, patient inclusion and exclusion criteria, interventions involved, and primary and secondary endpoints have been described in a previous publication [21]. In brief, patients were randomized into 2 groups: 1 group received half-dose PDT and the other group received HSML treatment. The same treatment, if deemed required at an evaluation visit at 6 to 8 weeks after the first treatment, could be repeated. The total duration of follow-up for all patients was 7 to 8 months.

The patients included were cases with active, chronic CSC, above 18 years of age with an accumulation of SRF on OCT and/or a subjective vision loss of more than 6 weeks. The patients had SRF that involved the fovea, together with presence of hyperfluorescent hot spots of leakage on fluorescein angiography (FA) and corresponding hyperfluorescent changes on indocyanine green angiography (ICGA). The baseline evaluation included fundus photography, OCT, fundus autofluorescence (FAF), FA, and ICGA, and the images were sent to a central reading center for assessment of the eligibility for inclusion.

Fundus photographs were obtained with a fundus camera from Topcon Medical Systems (Oakland, NJ, USA). OCT, FAF, FA, and ICGA were obtained with Spectralis HRA + OCT; (Heidelberg Engineering, Heidelberg, Germany). The subfoveal choroidal thickness (SFCT) was obtained by measuring the distance between Bruch's membrane and the outer scleral border or spectral-domain (SD) OCT.

\section{Choroidal vascularity index calculation}

The CVI calculation was done using a previously reported algorithm [24, 28]. Briefly, choroidal stroma and vessel area analysis involved (I) automated binarization of a highdefinition horizontal $6 \mathrm{~mm}$ OCT B-scan and (II) automated segmentation of the binarized choroid layer as reported previously [28]. The task of automated binarization involved (a) preprocessing, (b) exponential and non-linear enhancement, and (c) thresholding (Fig. 1b; Fig. 2b). The inter-observer variability of this CVI calculation has previously been reported to be $98 \%$ before shadow compensation [29]. The total subfoveal choroidal area and luminal area measured in a previous study both had an intraclass correlation coefficient of 94\% [22]. These previous findings indicate a robust interobserver variability of the CVI calculation.

\section{Statistical methods}

The data were compiled, tabulated, and analyzed using Statistical Package for the Social Sciences software (version 22; IBM Corp., New York, NY). Linear mixed model analyses were used to study the changes in BCVA, CVI, and SFCT over time and the correlation between CVI and BCVA in time. In the mixed model, BCVA was used as the dependent variable, time was used as a factor, and CVI was used as a covariate. $p$ values $\leq 0.05$ were considered statistically significant. A Pearson correlation test was performed in order to analyze the correlation between the CVI and SFCT. 

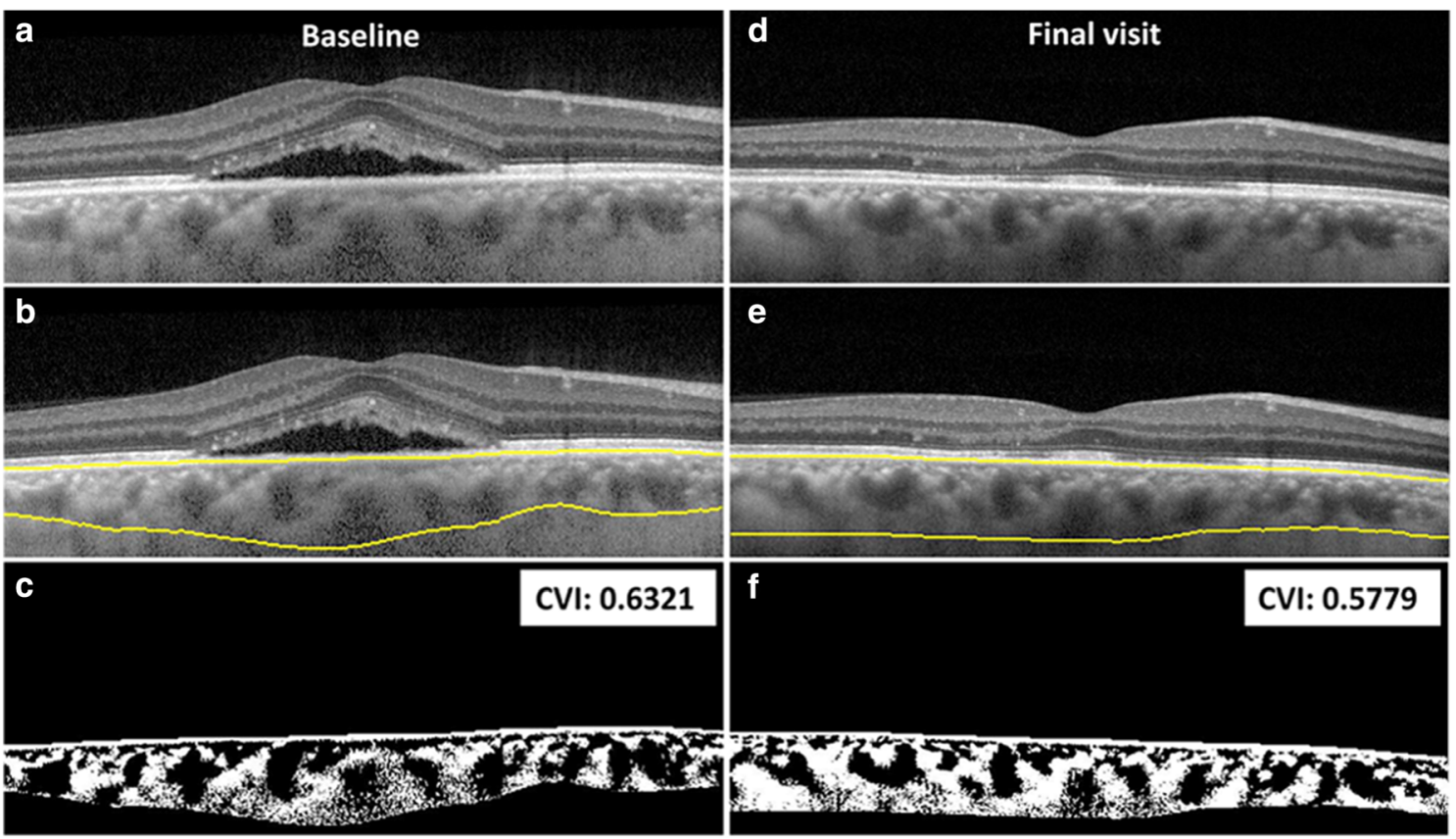

Fig. 1 Optical coherence tomography imaging of the right eye (a-f) of a 41-year-old male patient affected with chronic central serous chorioretinopathy and treated with HSML. Baseline imaging $(\mathbf{a}-\mathbf{c})$ and final visit imaging obtained 7-8 months later $(\mathbf{d}-\mathbf{f})$, including the yellow

\section{Results}

A total of 58 eyes of 58 patients were included in the analysis: 29 eyes each in the PDT and HSML group. OCT imaging and CVI measurements are shown from a patient treated with

segmentation lines $(\mathbf{b}, \mathbf{e})$ for the calculation of the CVI are depicted. The CVI is 0.6321 at baseline and changed to 0.5779 at final visit (change was not significant). CVI, choroidal vascularity index; HSML, high-density subthreshold micropulse laser

HSML and a patient treated with PDT in Fig. 1a-f and Fig. 2a-f, respectively. The study group mainly comprised males $(86.2 \%)$, and the mean ( \pm standard deviation $(\mathrm{SD}))$ age at presentation was $47.9 \pm 7.8$ years. The baseline demographics of both the HSML and PDT groups are depicted in Table 1. The
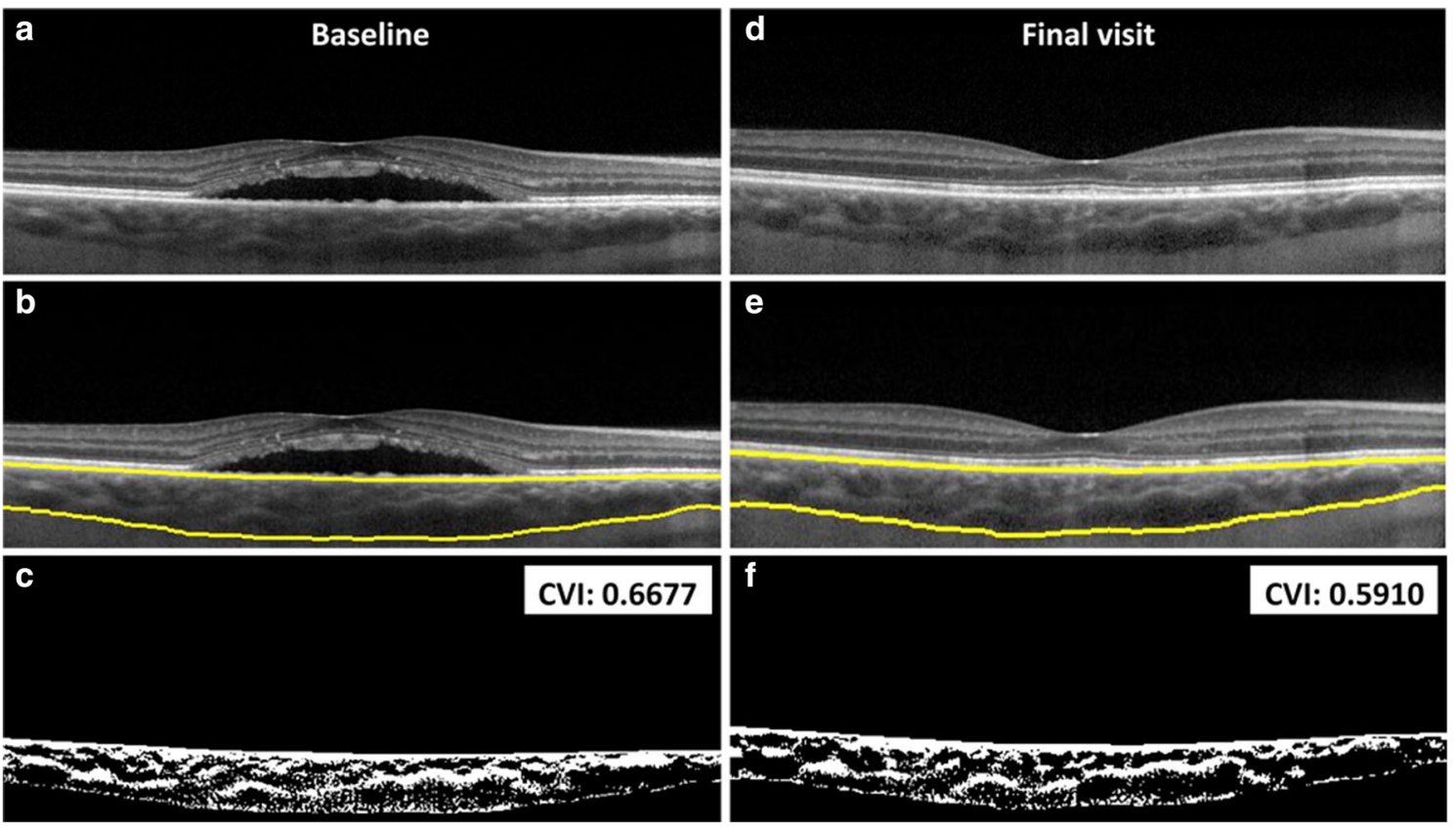

Fig. 2 Optical coherence tomography imaging of the right eye (a-f) of a 50 -year-old male patient affected with chronic central serous chorioretinopathy and treated with PDT. Baseline imaging $(\mathbf{a}-\mathbf{c})$ and final visit imaging obtained 7-8 months later $(\mathbf{d}-\mathbf{f})$, including the yellow

segmentation lines $(\mathbf{b}, \mathbf{e})$ for the calculation of the CVI are depicted. The CVI is 0.6677 at baseline and changed to 0.5910 at final visit. CVI, choroidal vascularity index; PDT, photodynamic therapy 
SFCT could not be measured in 3 patients at baseline and at an evaluation visit at 6 to 8 weeks after the first treatment. At final visit, the SFCT was unavailable in 6 patients. This was due to insufficient imaging quality of the SD-OCT scan.

\section{Changes in CVI and SFCT}

At baseline, the mean ( \pm SD) CVI for the total sample size was $0.6034 \pm 0.0346$, and at the last follow-up, CVI was $0.6025 \pm$ $0.0310(\Delta-0.09)$. The change in CVI, when comparing CVI before and after treatment for the 2 combined groups, was not significant $(p=0.452)$. A subanalysis involving PDT or HSML was also performed. The mean $( \pm \mathrm{SD})$ change in CVI in the HSML group between baseline and evaluation visit was $-0.0093 \pm 0.032$, which was not statistically significant $(p=0.127)$. In contrast, the patients in the PDT-treated group $(n=29$ eyes) had a minimal increase in CVI $(+0.0025 \pm$ $0.037)$, which was not statistically significant $(p=0.723)$. There was a mean change in CVI of +0.011 between baseline and final visit in the HSML group $(p=0.118)$, whereas a mean change in CVI of -0.013 between baseline and final visit $(p=0.080)$ was found in the PDT-treated group. In the HSML group, the mean SFCT was $417 \pm 116 \mu \mathrm{m}$ at baseline, $422 \pm 117 \mu \mathrm{m}$ at evaluation visit $(p=0.865)$, and $394 \pm$ $112 \mu \mathrm{m}$ at final visit ( $p=0.464$, compared to baseline). In the half-dose PDT group, mean SFCT was $438 \pm 114 \mu \mathrm{m}$ at baseline, $371 \pm 129 \mu \mathrm{m}$ at evaluation visit $(p=0.039)$, and $342 \pm 110 \mu \mathrm{m}$ at final visit ( $p=0.004$, compared to baseline).

\section{Correlation of CVI and SFCT}

In the HSML group, the Pearson correlation between the CVI change between baseline and final visit, and the SFCT change between baseline and final visit was $0.011(p=0.957)$. This Pearson correlation was 0.138 in the PDT group $(p=0.500)$.

\section{Correlation of CVI with BCVA}

A mixed model was computed to analyze the correlation between change in CVI and change in BCVA for the total sample size, and for the patients that were treated with either HSML or PDT treatment separately. When evaluating the total sample size, CVI was not correlated with BCVA (estimate $=18.90$, standard error $=26.79, p=0.483)$. When subanalyzing both treatment groups, CVI did not have a significant effect on BCVA in both the HSML group (estimate $=5.87$, standard error $=40.12, p=0.885$ ) and in the PDT group (estimate $=-4.73$, standard error $=39.06$, $p=0.904)$.

\section{Fellow eye}

Mean Early Treatment of Diabetic Retinopathy Study (ETDRS) BCVA in the HSML group was $88.8 \pm 7.6$ at baseline, $88.9 \pm 7.5$ at evaluation visit, and $88.8 \pm 9.3$ at final visit ( $p>0.999$, linear mixed model). In the half-dose PDT group, mean ETDRS BCVA was 87.9 \pm 7.6 at baseline, $88.3 \pm 7.5$ at evaluation visit 1 , and $88.6 \pm 8.6$ at final visit $(p=0.951$, linear mixed model).

Mean CVI in the HSML group was $0.597 \pm 0.040$ at baseline, $0.605 \pm 0.035$ at evaluation visit, and $0.596 \pm 0.037$ at final visit ( $p=0.586$, linear mixed model). The mean CVI in the half-dose PDT group was $0.610 \pm 0.036$ at baseline, 0.589 \pm 0.085 at evaluation visit, and $0.605 \pm 0.036$ at final visit ( $p=$ 0.350 , linear mixed model).

In the HSML group, the mean SFCT was $401 \pm 143 \mu \mathrm{m}$ at baseline, which decreased to $389 \pm 133 \mu \mathrm{m}$ at evaluation visit, and to $377 \pm 119 \mu \mathrm{m}$ at final visit $(p=0.799$, linear mixed model). In the half-dose PDT group, mean SFCT was $375 \pm 136 \mu \mathrm{m}$ at baseline, $378 \pm 143 \mu \mathrm{m}$ at evaluation visit, and $370 \pm 150 \mu \mathrm{m}$ at final visit $(p=0.977$, linear mixed model).
Table 1 Baseline characteristics of chronic central serous chorioretinopathy patients treated with either half-dose photodynamic therapy or high-density subthreshold micropulse laser

\begin{tabular}{|c|c|c|c|c|c|c|}
\hline & & \multicolumn{2}{|l|}{ HSML } & \multicolumn{2}{|c|}{ Half-dose PDT } & \multirow[t]{2}{*}{$p$ value } \\
\hline & & Count & Mean (SD) & Count & Mean (SD) & \\
\hline \multirow[t]{2}{*}{ Sex } & Male & $26(90 \%)$ & & $24(83 \%)$ & & 0.706 \\
\hline & Female & $3(10 \%)$ & & $5(17 \%)$ & & \\
\hline \multicolumn{2}{|c|}{ Age (in years) } & & $48 \pm 7.6$ & & $47 \pm 8.1$ & 0.622 \\
\hline \multicolumn{2}{|c|}{ BCVA at baseline (in ETDRS letters) } & & $76 \pm 10.3$ & & $78 \pm 8.2$ & 0.510 \\
\hline \multicolumn{2}{|c|}{ CVI at baseline } & & $0.61 \pm 0.031$ & & $0.60 \pm 0.037$ & 0.344 \\
\hline \multicolumn{2}{|c|}{ Choroidal thickness at baseline $(\mu \mathrm{m})$} & & $417 \pm 116$ & & $438 \pm 112$ & 0.496 \\
\hline
\end{tabular}

$B C V A$ best-corrected visual acuity, $C V I$ choroidal vascularity index, ETDRS Early Treatment of Diabetic Retinopathy Study, HSML high-density subthreshold micropulse laser, $P D T$ photodynamic therapy, $S D$ standard deviation 


\section{Discussion}

CSC is a chorioretinal disease characterized by increased choroidal thickness, hyperpermeability, and congestion of choroidal vessels $[4,5,30]$. Various studies have assessed these choroidal characteristics to assess and predict disease course and response to treatment $[26,31,32]$. CVI has recently been introduced as a marker of disease activity and has been reported to be increased in acute, chronic CSC ( $\mathrm{CCSC}$ ), and resolved CSC cases as compared to healthy controls [26].

In the first large multicenter randomized controlled trial (PLACE trial) on cCSC, patients that were treated with halfdose PDT were found to have a significantly higher percentage of complete resolution of SRF as compared to HSML [20]. After all, PDT is thought to primarily target the choroid, and after a short-term initial choroidal thickness increase, a reduction in choroidal thickness was found after PDT for cCSC, which may account for a post-treatment difference in CVI compared to HSML treatment [33]. In contrast to PDT, HSML is thought to primarily act through an effect on RPE function, although the precise mechanisms are unclear [11].

Somewhat surprisingly, we did not find a statistically significant reduction in CVI after either half-dose PDT or HSML in this prospective study. The superior anatomical and functional outcome of half-dose PDT in comparison to HSML treatment may therefore not be correlated with changes in CVI. Park et al. reported a significant decrease in CVI after half or full-dose PDT, and a significant increase in CVI after half-dose-half-fluence PDT [34]. This is in contrast with our study, since no significant changes in CVI were observed after half-dose PDT. In the study of Park et al., both acute CSC and cCSC patients were included, and the follow-up time within this study was only 3 months. Our study only included cCSC patients and had a follow-up of 8 months. These differences between the study of Park et al. and our study may explain the discrepancies in study findings, also given the possible differences between several entities within the pachychoroid/CSC spectrum [35]. The treatment effect of PDT may rather be a consequence of vascular remodeling of the choriocapillaris and larger choroidal vessels at the level of the vessel walls and their permeability, while their luminal density relative to the total choroidal area (calculated as CVI) may not be significantly affected. However, the choroidal thickness often decreases after half-dose PDT [36]. In the HSML group, we did not find an association between CVI change and the change in BCVA after treatment. HSML presumably may have an effect primarily on the RPE and does not directly affect choroidal vasculature.

In the untreated fellow eye, no significant changes in BCVA, CVI, and SFCT were observed, which may indicate that these parameters do not significantly change within a natural clinical course of 8 months. Effects of treatment on the contralateral eye are presumably negligible due to the local application of both treatments. Limitations of the current study were the relatively small sample size, and the relatively limited follow-up of 7 to 8 months. In addition, CVI is a relatively new endpoint and therefore limited studies are available. To assess whether an improvement in BCVA induced by either PDT or HSML may have a relationship with changes in CVI needs further validation with a larger sample size and longer follow-up.

In conclusion, both half-dose PDT and HSML treatment do not significantly affect CVI in chronic CSC. The treatment effects of both treatment modalities may therefore rely on other mechanisms, such as a reduction of choroidal hyperpermeability and leakage.

Funding information This research was supported by the following foundations: Stichting Macula Fonds, Retina Nederland Onderzoek Fonds, Stichting BlindenPenning, Algemene Nederlandse Vereniging ter Voorkoming van Blindheid, and Landelijke Stichting voor Blinden en Slechtzienden, which contributed through UitZicht, as well as Rotterdamse Stichting Blindenbelangen, Stichting Leids Oogheelkundig Ondersteuningsfonds, Haagse Stichting Blindenhulp, and Stichting Ooglijders. Prof. Camiel J.F. Boon was supported by a Gisela Thier Fellowship of Leiden University and a VENI grant of Netherlands Organization for Scientific Research. The funding organizations had no role in the design or conduct of this research. They provided unrestricted grants.

\section{Compliance with ethical standards}

Conflict of interest The authors declare that they have no conflict of interest.

Ethical approval All procedures performed were in accordance with the ethical standards of the institutional and/or national research committee and with the 1964 Helsinki declaration and its later amendments or comparable ethical standards.

Informed consent Informed consent was obtained from all individual participants included in the study.

Open Access This article is licensed under a Creative Commons Attribution 4.0 International License, which permits use, sharing, adaptation, distribution and reproduction in any medium or format, as long as you give appropriate credit to the original author(s) and the source, provide a link to the Creative Commons licence, and indicate if changes were made. The images or other third party material in this article are included in the article's Creative Commons licence, unless indicated otherwise in a credit line to the material. If material is not included in the article's Creative Commons licence and your intended use is not permitted by statutory regulation or exceeds the permitted use, you will need to obtain permission directly from the copyright holder. To view a copy of this licence, visit http://creativecommons.org/licenses/by/4.0/.

\section{References}

1. Gass JD (1967) Pathogenesis of disciform detachment of the neuroepithelium: II. Idiopathic central serous choroidopathy. Am J Ophthalmol 63(3):587/515-615/543. https://doi.org/10.1016/ 0002-9394(67)90027-X 
2. Lehmann M, Bousquet E, Beydoun T, Behar-Cohen F (2015) PACHYCHOROID: an inherited condition? Retina 35(1):10-16

3. Bouzas EA, Scott MH, Mastorakos G, Chrousos GP, KaiserKupfer MI (1993) Central serous chorioretinopathy in endogenous hypercortisolism. Arch Ophthalmol 111(9):12291233

4. Daruich A, Matet A, Dirani A, Bousquet E, Zhao M, Farman N, Jaisser F, Behar-Cohen F (2015) Central serous chorioretinopathy: recent findings and new physiopathology hypothesis. Prog Retin Eye Res 48:82-118

5. Gemenetzi M, De Salvo G, Lotery A (2010) Central serous chorioretinopathy: an update on pathogenesis and treatment. Eye 24(12): 1743

6. Mehta PH, Meyerle C, Sivaprasad S, Boon C, Chhablani J (2017) Preferred practice pattern in central serous chorioretinopathy. Br J Ophthalmol 101(5):587-590. https://doi.org/10.1136/ bjophthalmol-2016-309247

7. Chan W-M, Lai TY, Lai RY, Liu DT, Lam DS (2008) Halfdose verteporfin photodynamic therapy for acute central serous chorioretinopathy: one-year results of a randomized controlled trial. Ophthalmology 115(10):1756-1765

8. Piccolino FC, Eandi CM, Ventre L, De La Longrais RCR, Grignolo FM (2003) Photodynamic therapy for chronic central serous chorioretinopathy. Retina 23(6):752-763

9. Dhirani NA, Yang Y, Somani S (2017) Long-term outcomes in halfdose verteporfin photodynamic therapy for chronic central serous retinopathy. Clin Ophthalmol (Auckland, NZ) 11:2145-2149. https://doi.org/10.2147/opth.s151933

10. Erikitola OC, Crosby-Nwaobi R, Lotery AJ, Sivaprasad S (2014) Photodynamic therapy for central serous chorioretinopathy. Eye (London, England) 28(8):944-957. https://doi.org/10.1038/eye. 2014.134

11. Arsan A, Kanar HS, Sonmez A (2018) Visual outcomes and anatomic changes after sub-threshold micropulse yellow laser (577$\mathrm{nm})$ treatment for chronic central serous chorioretinopathy: longterm follow-up. Eye (London, England) 32(4):726-733. https://doi. org/10.1038/eye.2017.293

12. Maruko I, Koizumi H, Hasegawa T, Arakawa H, Iida T (2017) Subthreshold $577 \mathrm{~nm}$ micropulse laser treatment for central serous chorioretinopathy. PLoS One 12(8):e0184112

13. Ricci F, Missiroli F, Regine F, Grossi M, Dorin G (2009) Indocyanine green enhanced subthreshold diode-laser micropulse photocoagulation treatment of chronic central serous chorioretinopathy. Graefes Arch Clin Exp Ophthalmol 247(5):597-607. https://doi.org/10.1007/s00417-008-1014-1

14. Chen S-N, Hwang J-F, Tseng L-F, Lin C-J (2008) Subthreshold diode micropulse photocoagulation for the treatment of chronic central serous chorioretinopathy with juxtafoveal leakage. Ophthalmology 115(12):2229-2234

15. Breukink MB, den Hollander AI, Keunen JE, Boon CJ, Hoyng CB (2014) The use of eplerenone in therapy-resistant chronic central serous chorioretinopathy. Acta Ophthalmol 92(6):e488-e490. https://doi.org/10.1111/aos.12392

16. Singh RP, Sears JE, Bedi R, Schachat AP, Ehlers JP, Kaiser PK (2015) Oral eplerenone for the management of chronic central serous chorioretinopathy. Int J Ophthalmol 8(2):310-314. https://doi. org/10.3980/j.issn.2222-3959.2015.02.17

17. Bousquet E, Beydoun T, Zhao M, Hassan L, Offret O, Behar-Cohen F (2013) Mineralocorticoid receptor antagonism in the treatment of chronic central serous chorioretinopathy: a pilot study. Retina (Philadelphia, Pa) 33(10):2096-2102. https://doi.org/10.1097/IAE. 0b013e318297a07a

18. van Rijssen TJ, van Dijk EHC, Dijkman G, Boon CJF (2018) Clinical characteristics of chronic central serous chorioretinopathy patients with insufficient response to reduced-settings photodynamic therapy. Graefes Arch Clin Exp Ophthalmol 256(8):1395-1402. https://doi.org/10.1007/s00417-018-4003-z

19. van Rijssen TJ, van Dijk EHC, Yzer S, Ohno-Matsui K, Keunen JEE, Schlingemann RO, Sivaprasad S, Querques G, Downes SM, Fauser S, Hoyng CB, Piccolino FC, Chhablani JK, Lai TYY, Lotery AJ, Larsen M, Holz FG, Freund KB, Yannuzzi LA, Boon CJF (2019) Central serous chorioretinopathy: towards an evidence-based treatment guideline. Prog Retin Eye Res 73:100770. https://doi.org/ 10.1016/j.preteyeres.2019.07.003

20. van Dijk EHC, Fauser S, Breukink MB, Blanco-Garavito R, Groenewoud JMM, Keunen JEE, Peters PJH, Dijkman G, Souied EH, MacLaren RE, Querques G, Downes SM, Hoyng CB, Boon CJF (2018) Half-dose photodynamic therapy versus high-density subthreshold micropulse laser treatment in patients with chronic central serous chorioretinopathy: the PLACE trial. Ophthalmology 125(10):1547-1555. https://doi.org/10.1016/j.ophtha.2018.04. 021

21. Breukink MB, Downes SM, Querques G, van Dijk EH, den Hollander AI, Blanco-Garavito R, Keunen JE, Souied EH, MacLaren RE, Hoyng CB (2015) Comparing half-dose photodynamic therapy with high-density subthreshold micropulse laser treatment in patients with chronic central serous chorioretinopathy (the PLACE trial): study protocol for a randomized controlled trial. Trials 16(1):419

22. Agrawal R, Gupta P, Tan K-A, Cheung CMG, Wong T-Y, Cheng C-Y (2016) Choroidal vascularity index as a measure of vascular status of the choroid: measurements in healthy eyes from a population-based study. Sci Rep 6:21090

23. Sonoda S, Sakamoto T, Yamashita T, Shirasawa M, Uchino E, Terasaki H, Tomita M (2014) Choroidal structure in normal eyes and after photodynamic therapy determined by binarization of optical coherence tomographic images. Invest Ophthalmol Vis Sci 55(6):3893-3899. https://doi.org/10.1167/iovs.14-14447

24. Sonoda S, Sakamoto T, Yamashita T, Uchino E, Kawano H, Yoshihara N, Terasaki H, Shirasawa M, Tomita M, Ishibashi T (2015) Luminal and stromal areas of choroid determined by binarization method of optical coherence tomographic images. Am J Ophthalmol 159(6):1123-1131.e1121. https://doi.org/10.1016/j. ajo.2015.03.005

25. Lee M, Lee H, Kim HC, Chung H (2018) Changes in stromal and luminal areas of the choroid in pachychoroid diseases: insights into the pathophysiology of pachychoroid diseases. Invest Ophthalmol Vis Sci 59(12):4896-4908. https:// doi.org/10.1167/iovs. 18-25018

26. Agrawal R, Chhablani J, Tan K-A, Shah S, Sarvaiya C, Banker A (2016) Choroidal vascularity index in central serous chorioretinopathy. Retina 36(9):1646-1651

27. Agrawal R, Wei X, Goud A, Vupparaboina KK, Jana S, Chhablani J (2017) Influence of scanning area on choroidal vascularity index measurement using optical coherence tomography. Acta Ophthalmol 95(8):e770-e775. https://doi. org/10.1111/aos.13442

28. Vupparaboina KK, Nizampatnam S, Chhablani J, Richhariya A, Jana S (2015) Automated estimation of choroidal thickness distribution and volume based on OCT images of posterior visual section. Comput Med Imaging Graph 46(Pt 3): 315-327. https://doi.org/10.1016/j.compmedimag.2015.09. 008

29. Vupparaboina KK, Dansingani KK, Goud A, Rasheed MA, Jawed F, Jana S, Richhariya A, Freund KB, Chhablani J (2018) Quantitative shadow compensated optical coherence tomography of choroidal vasculature. Sci Rep 8(1):6461. https://doi.org/10. 1038/s41598-018-24577-8 
30. Nicholson B, Noble J, Forooghian F, Meyerle C (2013) Central serous chorioretinopathy: update on pathophysiology and treatment. Surv Ophthalmol 58(2):103-126

31. Maruko I, Iida T, Sugano Y, Ojima A, Ogasawara M, Spaide RF (2010) Subfoveal choroidal thickness after treatment of central serous chorioretinopathy. Ophthalmology 117(9):1792-1799. https:// doi.org/10.1016/j.ophtha.2010.01.023

32. Spaide RF, Koizumi H, Pozonni MC (2008) Enhanced depth imaging spectral-domain optical coherence tomography. Am J Ophthalmol 146(4):496-500

33. Imamura Y, Fujiwara T, Margolis R, Spaide RF (2009) Enhanced depth imaging optical coherence tomography of the choroid in central serous chorioretinopathy. Retina (Philadelphia, Pa) 29(10):1469-1473. https://doi.org/10. 1097/IAE.0b013e3181be0a83

34. Park W, Kim M, Kim RY, Park YH (2019) Comparing effects of photodynamic therapy in central serous chorioretinopathy: full- dose versus half-dose versus half-dose-half-fluence. Graefes Arch Clin Exp Ophthalmol. https://doi.org/10.1007/s00417-019-044268

35. Cheung CMG, Lee WK, Koizumi H, Dansingani K, Lai TYY, Freund KB (2018) Pachychoroid disease. Eye (London, England) 33(1):14-33. https://doi.org/10.1038/s41433-018-0158-4

36. van Rijssen TJ, van Dijk EHC, Scholz P, Breukink MB, BlancoGaravito R, Souied EH, Keunen JEE, MacLaren RE, Querques G, Fauser S, Downes SM, Hoyng CB, Boon CJF (2019) Focal and diffuse chronic central serous chorioretinopathy treated with halfdose photodynamic therapy or subthreshold micropulse laser: PLACE trial report no. 3. Am J Ophthalmol 205:1-10. https://doi. org/10.1016/j.ajo.2019.03.025

Publisher's note Springer Nature remains neutral with regard to jurisdictional claims in published maps and institutional affiliations. 